Vol. 12 (1): 67-76 (2022)

\title{
ASSOCIATION OF DELIVERY MODE AND BREASTFEEDING
}

\author{
Risida Gjonej $^{1 *}$, Albana Poloska ${ }^{1}$, Etleva Smakaj ${ }^{1}$, Valbona Bezhani ${ }^{1}$, Flora Zyberaj ${ }^{1}$ \\ ${ }^{1 *}$ University of Medicine, Faculty of Technical Medical Sciences, Tirana, Albania; \\ 1*Corresponding Author Risida Gjonej, e-mail: gjonejrisi@yahoo.com;
}

Received October 2021; Accepted November 2021; Published January 2022;

DOI: https://doi.org/10.31407/ijees12.108

\begin{abstract}
Breast milk is a rich fluid. The benefits of it already are worldwide known because there are a lot of studies that show it. But there are some factors that affect the process or the choice of feeding with breast milk like as mother and fetal conditions. This study aims to describe the association between mood of delivery and breastfeeding and especially the initiation of the breastfeeding How the breast's condition affects the breastfeeding. This is a point (cross-sectional) study, which was implemented for a period of 5 months during the years 2018-2019. The survey included 200 women with a distribution by race, educational level, age, number of pregnancies, mode of delivery, number of abortions, etc. The study used a questionnaire with structured and semi-structured questions through which information was obtained on a number of general elements and mainly those related to the way the birth process and the impact on breastfeeding. The results show that the age group with the greatest involvement in this study is $19-29$ years old with $51.5 \%$ followed by the age group $30-39$ years old with $47 \%$ and only $1.5 \%$ are in the age group over 39 years' old. Mothers with higher educational level $(49.7 \%)$ followed by mothers with 8 years of schooling (29.1\%) and mothers with high school (19.9\%). 50\% of mothers delivery by normal delivery and $49 \%$ of them by cesarean- section. There is a statistically significant relationship between the delivery mode and breastfeeding, $\chi 2=4.348, \mathrm{P}<0.05(\mathrm{P}=.037)$; between the delivery mode and the time of starting breastfeeding, $\chi 2=$ $6.943, \mathrm{P}<0.05(\mathrm{P}=.031)$.
\end{abstract}

Keywords: normal delivery, cesarean section, breastfeeding. 